\title{
GENETIC DETERMINANTS OF OSTEOPOROTIC RISK IN CALCIUM-DEPENDENT DISEASES - CHRONIC PANCREATITIS AND HYPERTENSIVE DISEASE
}

\author{
Viun T.I., Pasieshvili L.M.
}

\author{
Kharkiv National Medical University, Ukraine
}

\begin{abstract}
Objectives: to determine the genetic determinants of osteoporotic risk in the comorbidity of calcium-dependent diseases - chronic pancreatitis and hypertensive desease. Subjects and methods: two groups of patients were formed for the study - the main one -70 patients with chronic pancreatitis and hypertensive disease; and the comparison group - 40 persons with isolated course of chronic pancreatitis. The polymorphism of VDR, LCT and FDPS genes as well as the comparison of pathological alleles of these genes was investigated with the definition of the possible influence of these indices on the course of the disease and formation of complications. Results show that patients with a combined course of $\mathrm{CP}$ and HD have an increased risk of osteoporosis, which is expressed by an increase in the number of fractures compared with healthy people. As the genetic determinants of the development of osteopenic syndrome in these patients, there is the presence of the allele of the VR gene, the VDR gene and the SS allele of the FDPS gene. The presence of the LC allele of the LCT gene has no independent predictive value, but in combination with the identified variants of the genes, VDR and FDPS promote an increase in osteoporosis risk.

Key words: chronic pancreatitis, hypertonic disease, osteoporosis, VDR gene polymorphism, LCT gene polymorphism, FDPS gene polymorphism.
\end{abstract}

\section{Introduction}

At present, diseases of the joints, bones and the spine are often considered to be complications arising from the comorbidity of many diseases of the internal organs. So, it has been proven that the presence of overweight and obesity contributes to the formation of osteoarthritis, especially of knee joints, which is the result of not only mechanical pressure on the joint, but also the effects of hormones-like substances (e.g. apelin-13) produced by fatty tissue [6]. In addition, it has been shown that the development of obesity over the $2^{\text {nd }}$ stage is a prognostic disadvantage for the development of osteoporotic changes [7]. Similar changes in joints and bone tissue occur in patients with diabetes mellitus, which is associated not only with the effect of adipocytes hormone-

\footnotetext{
Corresponding Author:

Tetiana Viun, MD, PhD student Department

of General Practice - Family Medicine of

Kharkiv National Medical University, Ukraine.

E-mail: viun.tatiana@gmail.com
}

like substances but also with the malfunction of microcirculation and all types of exchange [18].

It is proved that changes in bone tissue, namely imbalance in the parameters of calcium metabolism, are indicative for patients with coronary artery disease. At the same time, calcium coming out of bones precipitates on vessels, thus triggering not only the development of osteopenic states, but also atherosclerosis [4].

These data were the basis for the formation of a group of diseases, the course of which is accompanied by changes in the indices of bone marrow markers: either due to increased losses of calcium matrix, or lack of its components for the proper formation of bones, that is, contribute to the damage to both joints and their derivatives, as well as bones themselves. These diseases were called calcium-dependent, and their course was associated with the formation of secondary osteoporosis $[9,14]$. These diseases include disorders of the esophagus, cardiovascular and endocrine systems, etc. 
The World Health Organization has officially identified OP as one of the ten most important chronic diseases of humanity, as it is very widespread, has a clear definition, diagnostic methods, and sufficient opportunities for prevention and treatment. OP is a systemic disease of the skeleton from the group of metabolic bone diseases, characterized by a decrease in bone mass and a violation of bone marrow microarchitectonics, which leads to a reduction in bone strength and, consequently, to an increased risk of fractures $[5,13]$. Bone tissue plays a major role in calcium homeostasis regulation [11].

Development of chronic gastrointestinal diseases undoubtedly has a negative impact on calcium metabolism. Thus, the emergence of maldigestion syndromes and malabsorption in many diseases of the digestive tract leads to impairment of the absorption of mineral and organic substances, contributes to the formation of hypocalcemia and, ultimately, a decrease in mineral density of bone tissue $[12,19]$. Chronic pancreatitis is one of the diseases negatively affecting bone metabolism [15]. The long course of the disease, its recurrent nature, accompanied by a disturbance in the absorption of many macroand micronutrients, promotes the formation of a pathological process, that is, secondary osteoporosis [3].

Hypertensive disease is another common disorder that makes a significant contribution to the development of OP [8]. Systemic vascular lesion with the formation of endothelial dysfunction, one of the mechanisms of which is the interaction of pro- and anti-inflammatory immune mechanisms, cell membrane disruption as current changes in the composition of fatty acids, and the imbalance of the POL-AOS processes, the effect of diseases on the macroelemental composition of the body and vitamin balance should be considered as a common pathogenic link between CP and HD [2]. In this case, it can be assumed that the common pathogenic links can increase and contribute to the development of complications, not only due to their combination, but also provoked by each nosological form. The combination of HD and CP potentiates two directions of calcium loss: with HD due to changes in the redistribution of potassium-sodium-calcium mechanism between cell and extracellular space, which requires an additional "presence" of calcium. At the same time, CP is characterized by an impairment of its absorption, as a result of inadequate digestion of food and diarrhea, and in this case, vitamin imbalance - lack of vitamin D as a result of intake and absorption [2, 14]. That is, comorbidity of HD and $\mathrm{CP}$ triggers aggravating preconditions that operate in different directions, but lead to the same result, calcium metabolism disruption $[1,3]$.

Several researchers have determined that the development of diseases and their complications may be the result of the presence of candidate genes and their adverse polymorphism may provoke changes in pathogenic trends in the course of diseases. That is, a combination of diseases can occur not only accidentally in a particular patient, but is a result of a coincidence of a number of circumstances, among which the leading role belongs to genetic aberrations. Among the many genes involved in the regulation of bone metabolism, the special role belongs to the gene of receptors of vitamin D (VDR), lactase gene (LCT) and farnesyl diphosphates synthase gene (FDPS) [5, 10, 16, 17].

That is, participation of these genes can be considered as a leading factor in the formation of secondary osteoporosis.

2 Purposes, subjects and methods:

2.1 Purpose - to determine genetic determinants of osteoporosis at comorbidity of calcium-dependent diseases - chronic pancreatitis and hypertensive disease.

\subsection{Subjects \& Methods}

The study involved 110 patients with $\mathrm{CP}$ and in 70 cases CP was accompanied by HD (main group). The comparison group included 40 patients with isolated course of CP. There were more women ( 73 persons $-66.4 \%$ ) than men. The age of the patients ranged from 29 to 43 years and on average in groups it was $33.2 \pm 2.1$ (main) and 32.9 \pm 3.1 (comparison). The control group included 78 practically healthy persons of the same age and gender, which allowed us to compare the findings.

Verification of the diagnosis of HD, the determination of the stage and degree of the disease was carried out in accordance with the recommendations of the European Society of Hypertension (ESH) for the management of arterial hypertension (2009) and the recommendations of the Working Group on Arterial Hypertension of the Ukrainian Association of Cardiologists (2012).

The diagnosis of $\mathrm{CP}$ was determined on the basis of patient's presentation, history taking, clinical, laboratory and instrumental findings, referring to the Order of the Ministry of Health of Ukraine No. 271 dated 13.06.2005, updated on 10 September 2014 by Order No. 638 . 
The state of excretory function of PG was assessed by the level of pancreatic elastase- 1 in serum of patients. The evaluation was carried out by the immune enzyme method using the commercial test systems of ScheBo (Germany), according to the enclosed instructions for the immune enzyme analyzer Labline-90 (Australia). Structural state of PG was determined during ultrasound.

Measurement of blood pressure (BP) was performed according to the Unified clinical protocol of medical aid for arterial hypertension, approved by the Order of the Ministry of Health of Ukraine as of 24.05.2012 No.384. Determination of vitamin $\mathrm{D}$ receptor gene polymorphism, LCT gene $13910 \mathrm{C} / \mathrm{T}$ marker polymorphism and farnesyl diphosphates synthase polymorphism (FDPS c.IVS1 T-99G) was performed using the sets of "Litehh" (Russia) by the polymerase chain reaction method for realtime amplification using fluorescent labels on the moderate degree of excretion of pancreatic insufficiency (43-61.4\% and 25-62.5\%, respectively). A slight degree of violation of enzymes synthesis was observed in $38.6 \%$ and $37.5 \%$ of patients, respectively. Patients with severe form of excretory insufficiency were not involved. Ultrasound examination and clinical presentation confirmed chronic pancreatitis: inflammation and inflammatory tissues were determined in the gland.

The analysis of the frequency and nature of disorders of the structural and functional state of bone tissue SFSBT verified by absorption method and according to DEXA data showed that 33 persons $(30 \%)$ of 110 patients with $\mathrm{CP}$ had changes in bone mineral density (BMD). In this case, in the main group, signs of osteoporosis were confirmed in 11 cases $(15.7 \%)$, and osteopenia in 12 cases $(17.1 \%)$. In the comparison group, these figures were $10 \%$ and $15 \%$ respectively (table).

Frequency and nature of disorders of the structural and functional state of bone tissue in patients with CP combined with HD and isolated $C P$ verified by absorption method

\begin{tabular}{|l|c|c|c|c|c|c|c|c|}
\hline \multirow{2}{*}{$\begin{array}{c}\text { Patients with CP combined } \\
\text { with HD and isolated CP }\end{array}$} & \multicolumn{6}{c|}{$\begin{array}{c}\text { Structural-functional state } \\
\text { of bone tissue according to DEXA }\end{array}$} \\
\cline { 3 - 9 } & \multicolumn{2}{|c|}{ Osteopenia } & Osteoporosis & $\begin{array}{c}\text { Without } \\
\text { impairments }\end{array}$ \\
\hline Number of patients & abs. & $\%$ & abs. & $\%$ & abs. & $\%$ & abs. & $\%$ \\
\hline Main group & 70 & 100 & 12 & 17,1 & 11 & 15,7 & 47 & 67.2 \\
\hline Comparison group & 40 & 100 & 6 & 15 & 4 & 10 & 30 & 75 \\
\hline
\end{tabular}

Rotor-Gene тм 6000 six-channel analyzer ("Corbett Research", Australia).

The analysis of the frequency and nature of absorbtionally-verified violations of SFSBT (structural and functional state of bone tissue) was performed according to the X-ray examination by dual-energy X-ray absorptiometry (DEXA).

The obtained data were processed by analysis of the tables using Statistica software package. The statistical significance of the results was evaluated using the $\chi$-square Pearson criterion.

Conflict of interests. There is no conflict of interests.

\section{Results and discussion}

All patients with HD had stage II and level 2 of arterial hypertensive disease: mean systolic blood pressure in the group was $164 \pm 6.3 \mathrm{mmHg}$ and diastolic $98.4 \pm 3.1 \mathrm{mmHg}$, which was confirmed by the characteristic changes in the ECG and the detection of violations in the target organs.

The majority of patients in the main group and in the pancreatic elastase-1 group had a
The analysis of the frequency and nature of SFSBT impairment verified by absorption method showed that in patients with the combined course $\mathrm{CP}$ and HD, these violations were observed in a greater number of patients than in the comparison group $(23(32,9 \%)$ versus $10(25 \%)$ patients, respectively); however, there were no differences in the statistical significance.

At the same time, the analysis of the history data showed that both in the main group of individuals and in the comparison group, patients had previous limb fractures 29 $(41.4 \%)$ and $4(10 \%)$, respectively. However, these statistical data do not always coincide with SFSBT factors, namely, the impairment of the structural and functional status of bone tissue in the main group in the densitometric study was observed less often - 23 versus 29. This discrepancy had no statistical significance and was most likely due to the peculiarities of the group being examined young people with a mobile lifestyle and, consequently, possible traumatic situations. 
Thus, we can conclude that concomitant hypertension in patients with $\mathrm{CP}$ complicates the course of OP.

In determining the polymorphism of the receptor gene of vitamin $D$, a statistically significant dependence on the distribution of gene alleles from the group of patients was revealed $(\chi 2=30.08, \mathrm{df}=4, \mathrm{p}<0.01)$. Thus, according to the results of genetic testing, control patients were divided into three groups. Thus, the first Group 1 included 17 patients (24.3\%) who were carriers of the bb genotype; Group 2 - carriers of the $\mathrm{Bb}$ genotype - 34 $(48.6 \%)$ and Group 3 - carriers of the BBgenotype -19 persons $(27.1 \%)$. In the group of patients with isolated $\mathrm{CP}$, genotype bb was in $22.5 \%$ of patients ( 9 cases); BB $-35 \%$ (14) and $\mathrm{Bb}-42.5 \%$ (17 cases). When combined with $\mathrm{CP}$ and $\mathrm{HD}$, the distribution was as follows: $15.7 \%$ ( 11 cases), $51.4 \%$ (36 cases) and 32.9\% (23 cases), respectively. Thus, the overwhelming majority of patients with $\mathrm{CP}$, combined with $\mathrm{HD}$ (58.6\%), had an abnormal BB allele, which was 1.7 times more frequent than in the comparison group and 2.2 times in relation to the control group.

The frequency distribution of genotypes and alleles of the LCT gene in the control group corresponded to the following: $\mathrm{T} / \mathrm{T}$ genotype was found in $19.2 \%(\mathrm{n}=15), \mathrm{C} / \mathrm{T}$ genotype in $32.1 \%$ $(\mathrm{n}=25)$ and $\mathrm{C} / \mathrm{C}$ genotype in $48.7 \%(\mathrm{n}=38)$. In the comparison group, $\mathrm{T} / \mathrm{T}$ genotype was found in $17.5 \%$ of patients $(n=7)$; the genotype of the $\mathrm{C} / \mathrm{T}$ gene of LCT was observed in $27.5 \%$ of the subjects $(\mathrm{n}=11)$ and $\mathrm{C} / \mathrm{C}$ genotype was $55 \%$ $(n=22)$. Assessment of the distribution of genotypes and alleles in the main group of patients showed $\mathrm{T} / \mathrm{T}$ genotype in 11 patients $(15.7 \%)$, $\mathrm{C} / \mathrm{T}$ genotype in $20(28,6 \%)$ and $\mathrm{C} / \mathrm{C}$ genotype in 39 patients with a combination of $\mathrm{CP}$ and $\mathrm{HD}$, which was $55.7 \%$. Thus, changes in the polymorphism of C/C genotype of the LCT gene in patients with chronic $\mathrm{CP}$ and in combination with $\mathrm{CP}$ and HD did not have any significant differences with regard to control.

The statistically significant nature depended on the genotypes of the polymorphic FDPS gene $(\chi 2=23.58, \mathrm{df}=2, \mathrm{p}<0.01)$. In the control group, the carriers of SS genotype were represented by 2 individuals $(2.6 \%)$, there were 24 carriers of AS genotype $(30.8 \%)$, and AA genotype was found in 52 patients $(66.6 \%)$. In the comparison group (CP patients), SS genotype was found in $22.5 \%$ of cases ( 9 people), AS in $37.5 \%$ (15) and
AA in $40.0 \%$ (16) In patients with combined CP and HD, the FDPS gene polymorphism was found in $30.0 \%$ (21 cases), $22.9 \%$ (16) and $47.1 \%$ (33), respectively.

Thus, comparison with control in patients of both groups showed an "increase" in the frequency of SS genotype: $2.6 \pm 1.8 \%$ in control; $22.5 \pm 6.6 \%$ and $30.0 \pm 5.5 \%$ for $\mathrm{CP}$ and its combination with $\mathrm{HD}$, respectively, with the decrease in the frequency of AA genotype (66.7 $\pm 5.3 \%, 40.0 \pm 7.7 \%, 471 \pm 6.0 \%$, respectively).

Comparison of the pathological alleles of all three genes for the general sample of patients (188 cases) was the largest number of cases of the combination of pathological alleles of the VDR gene, the CT gene of the LCT and CC of the FDPS gene $-38.9 \%$, this value is statistically significant (Pearson Chi- square, $\chi 2=9.06011$, $\mathrm{df}=4, \mathrm{p}=0.05$ ). The data is presented in fig. 1 .

In the distribution of the frequencies of the VDR, LCT and FDSP genes in patients with isolated CP $(n=40)$, the highest number of cases was the combination of pathological alleles of the VB gene of the VDR gene, the CC of the LCT gene and the AC of the FDPS gene of $40.4 \%$.

In connection with a significant increase in the dimension of the tables in the consistent analysis of the three genes, the results should be considered as a hypothesis describing the tendency of the phenomenon under study (fig. 2).

The results of the comparison of pathological alleles in the $\mathrm{CP}$ group combined with $\mathrm{HD}(\mathrm{n}=$ 70) also have the status of a hypothesis concerning the trend of a compatible distribution. The combination of pathological alleles of the VDR gene of the VDR gene, the CC of the LCT gene and the CC of the FDPS gene was $40.7 \%$ (fig. 3).

Thus, we can state that as a result of a small sample, most data do not have statistically significant results, and the resulting distributions can only be considered as a tendency. With a consistent analysis of the three genes, the tendency of the pathological alleles B of the VDR gene and the allele $\mathrm{C}$ of the gene LCT and FDPS

\section{Conclusions}

Patients with CP and HD are patients with an increased risk of osteoporosis, manifested by an increase in the number of fractures (without a clear association with changes in BMD) as compared to healthy subjects. As the genetic determinants of the development of osteopenic syndrome in these patients, there is the presence of the allele of the BB gene of the VDR gene 


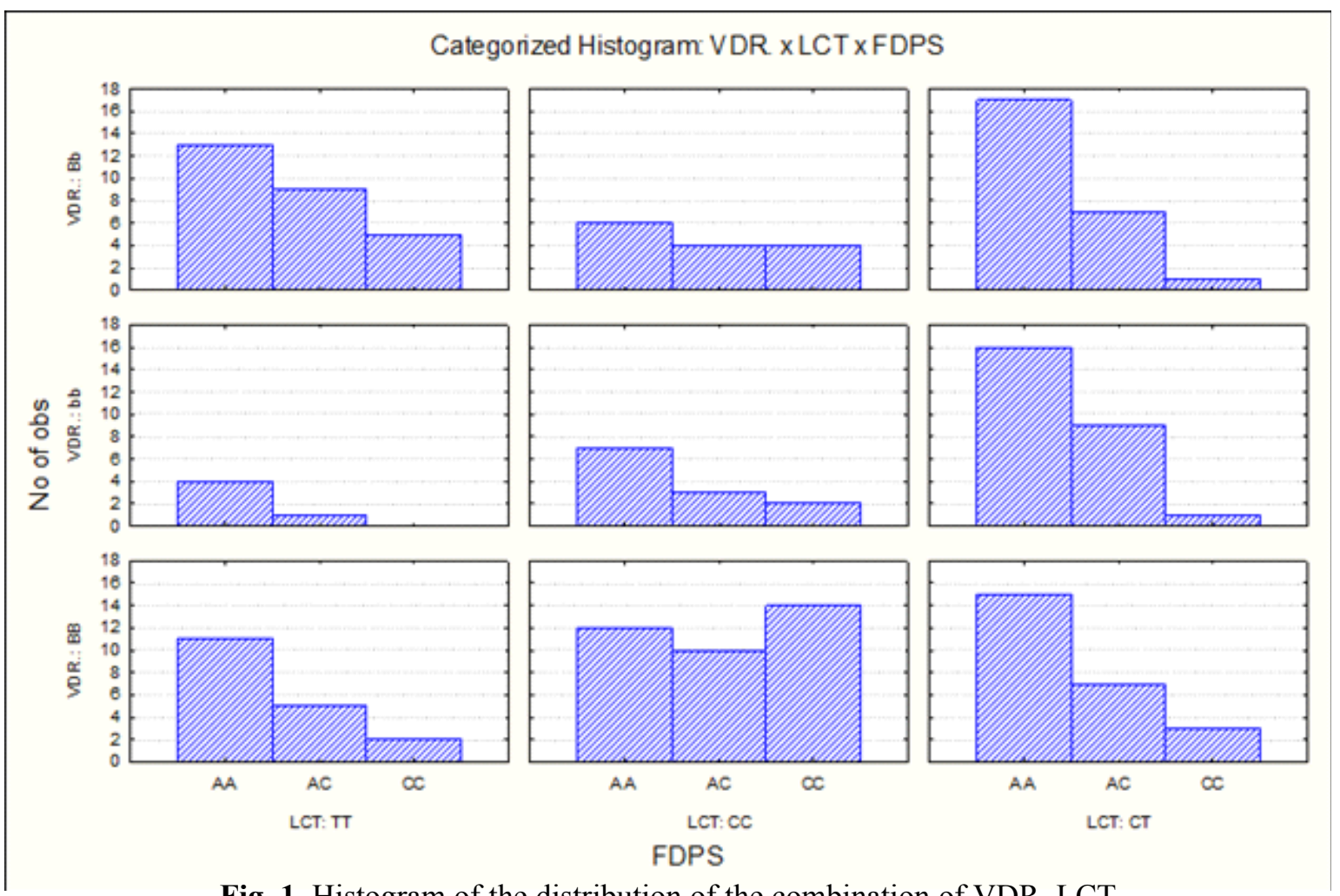

Fig. 1. Histogram of the distribution of the combination of VDR, LCT and FDSP genes in the total sample of patients

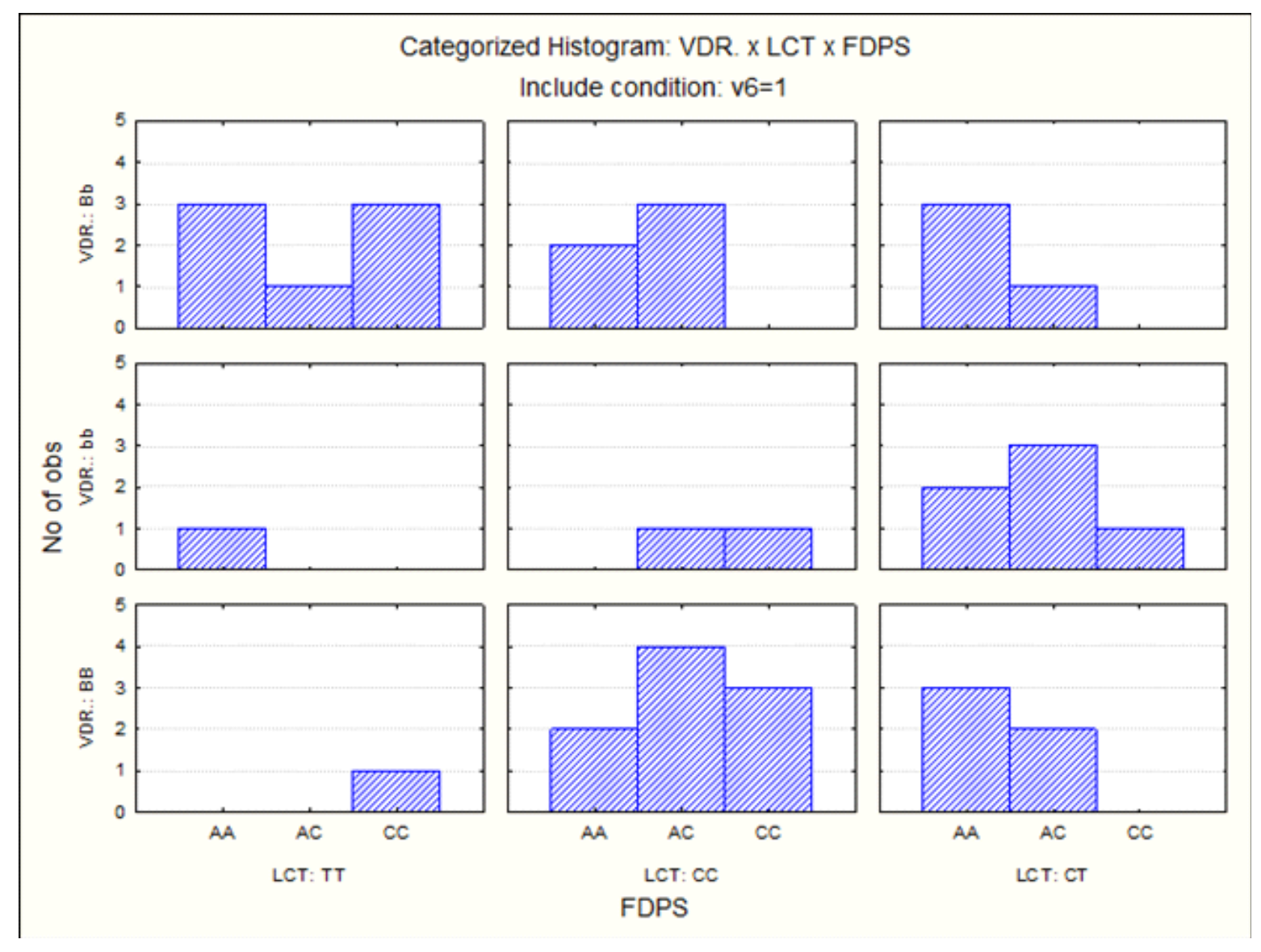

Fig. 2. Distribution histogram of the combination of VDR, LCT and FDSP genes in patients with isolated CP 


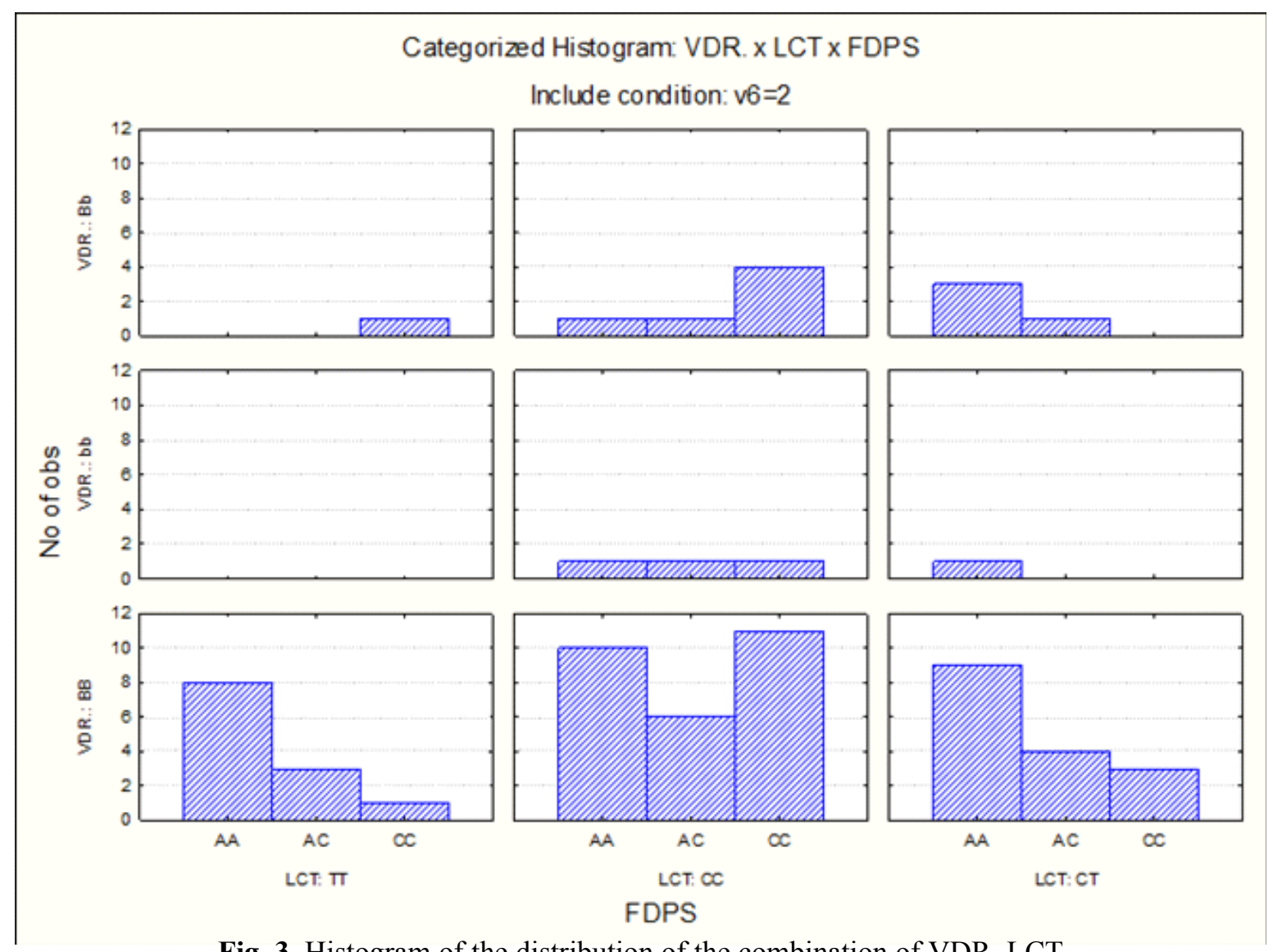

Fig. 3. Histogram of the distribution of the combination of VDR, LCT and FDSP genes in patients with $\mathrm{CP}$ accompanied by HD

and the $\mathrm{CC}$ allele of the FDPS gene. The presence of the CC allele of the gene LCT has no independent predictive value, but in combination with the identified variants of the genes, VDR and FDPS trigger an increase in the risk of osteoporosis.
Prospects for further research are related to the substantiation of genetic research for early diagnosis and prevention of the risk of osteopenic states in people with comorbidity of chronic pancreatitis and arterial hypertension.

\section{References}

1. Babinets L.S., Kvasnyska O.S., Mignenko L.M., Pinkevich O.Ya. (2011). Osteodeficiency and the effect of concomitant pathology on its depth in chronic pancreatitis. Bukovinsky medical bulletin, V15, № 2(58), 183-185

2. Viun T. I. (2018). Mechanisms of implementation of osteopenic states in patients with the combined course of chronic pancreatitis and hypertension. Vestnik club of pancreatologists, № 4 (41), 36-41.

3. Viun T.I., Pasieshvili L.M. (2018). Priorities of the diagnostic search of osteopenic conditions in patients with chronic pancreatitis and hypertension. Ukrainian Recognition of scientific and practical specialties. Suchasna Gastroenterologiya, № 3(101), 14-20.

4. Ivanova K.V. (2018). Dynamics of indicators of remodulation, resorption of bone tissue and lipid profile of blood in patients with coronary heart disease depending on the body mass index. Modern medicine: trends and prospects of development: a collection of materials of international scientificPractical Medical Conference (Republic of Poland, Rzeszow, July 9, 2018), 91-94.

5. Krylov M.Y., Nikitinskaya O.A., Samarkina E.Y., Demin N.V., Toroptsova N.V. (2016). Farnesyl diphosphate synthase (fdrs) and geranylgeranyl diphosphate synthase (ggsp1) gene polymorphisms and efficiency of therapy with bisphosphonates in russian women with postmenopausal osteoporosis: a pilot study. Rheumatology Science and Practice, 54(1), 49-52. doi.org/10.14412/1995-4484-2016-49-52

6. Tereshkin K.I. (2015). Role of determination of genetic markers and apelin levels in patients with osteoarthritis on the background of obesity in clinical practice. Materials of NPK with international 
participation "Chronic non-communicable diseases: measures of prevention and control of complications", Kharkiv, 210-211.

7. Tereshkin K.I., Pasieshvili L.M. (2016). Prognostic and diagnostic value of apelin during osteoarthrosis in patients with obesity. Problems of Endocrine Pathology, Issue 2, 70-75.

8. Bang D., Xu J., Keenan R., Pike V., Lehmann R., Tenner C., Crittenden D., Pillinger M., Krasnokutsky S. (2016) Cardiovascular Disease Prevalence in Patients with Osteoarthritis, Gout, or Both. Bulletinofthe Hospital Joint Disease, 74, 113-8.

9. Duggan S.N., O'Sullivan M., Hamilton S., Feehan S.M., Ridgway P.F., Conlon K.C. (2012). Patients with chronic pancreatitis are at increased risk for osteoporosis. Pancreas., 41(7), 1119-24. doi: 10.1097/ MPA.0b013e31824abb4d

10.Haussler M.R., Whitfield G.K., Kaneko I., Haussler C.A., Hsieh D., Hsieh J.C., Jurutka P.W. (2013). Molecular mechanisms of vitamin D action. Calcif Tissue Int., 92(2), 77-98. doi: 10.1007/ s00223-012-9619-0

11. Hoes J. N. (2015) Management of osteoporosis in rheumatoid arthritis patients. Expert Opin. Pharmacother, 16(4), 559-571.

12. Institute of Medicine (US) Committee to Review Dietary Reference Intakes for Vitamin D and Calcium (2011). Ross A. C., Taylor C. L., Yaktine A. L. et al. Dietary Reference Intakes for Calcium and Vitamin D. Washington (DC): National Academies Press (US). Available from: http://www.ncbi.nlm.nih.gov/ books/NBK56070.

13. International Society for Clinical Densitometry, The. Official positions 2015 ISCD combined: official positions of the international society for clinical densitometry. Available at: www.ISCD.org. June 2015.

14. Kendir C., van den Akker M., Vos R. (2017). Cardiovascular disease patients have increased risk for comorbidity: A cross-sectional study in the Netherlands. Eur. J. Gen. Pract. № 23, 1-6.

15.Manohar M., Verma A.K., Venkateshaiah S.U. (2017) Pathogenetic mechanisms of pancreatitis. World J. Gastrointest. Pharmacol, Vol. 8, № 1, 10-25.

16. Marozik P., Mosse I., Alekna V., Rudenko E. (2013). Association Between polymorphisms of VDR, COL1A1 and LCT genes and Bone Mineral Density in Belarusian women with severe postmenopausal osteoporosis. Medicina (Kaunas), 177-183.

17.Olmos J.M., Zarrabeitia M.T., Hernandez J.L. (2012) Common allelic variants of the farnesyl diphosphate syntase gene influence the response of osteoporotic women to bisphosphonates. Pharmacohenom J., 12, 227-32. doi: 10.1038/tpj.2010.88

18. Riancho J.A. (2018) Epigenetics of Osteoporosis: Critical Analysis of Epigenetic Epidemiology Studies. Curr. Genom. V.6, 405-410.

19. Viun T., Pasieshvili L. (2018). Pathogenetic links of the combined course of chronic pancreatitis and hypertensive disease and their role in the formation of complications. Georgian medical news, № 10(283), 81-84.

Received: 17-Jan-2019

Accepted: 11-Mar-2019 